\title{
Implications of Individual Differences, Social-Structural Constraints, and Choice for STEM Representation
}

\author{
Brenton M. Wiernik \\ University of South Florida \\ Anne-Grit Albrecht \\ Leuphana University Lüneburg
}

\author{
Bart Wille \\ University of Antwerp \\ Karl J. Petersen \\ Institut Curie
}

\begin{abstract}
In this commentary on Miner et al. (2018), we highlight the role of both individual differences and social-structural factors for gender representation in STEM. We emphasize that women are active agents in guiding their own careers and that women make choices which optimize their goal pursuit in light of their individual differences traits, personal experiences, and environmental contexts. We discuss implications for career guidance and other areas of I-O practice that recognizes women's agency in choosing their own career goals. Recognizing the role of individual choices in guiding careers does not preclude the existence or influence of social-structural factors on these choices and is not an "excuse" to justify societal or structural inequities. Addressing gender differences in STEM representation requires understanding the choices women make about their careers and the factors influencing these choices.
\end{abstract}

Keywords: gender, interests, personality, career development, abilities, STEM

Both individual differences and social-structural factors impact for gender representation in STEM and discuss implications for practice that recognizes women's agency in choosing their own career goals. Women (as well as men and non-binary persons) are active agents who make a series of choices throughout their lives about the type of work they pursue and how their careers develop and progress. These choices are strongly driven by individuals seeking careers that fit their individual differences traits, including interests, values, personality traits, and abilities (Hansen, 2013). Critically, individuals do not make choices in a vacuum, but actively adapt to their life experiences and perceived environmental opportunities and constraints to best fulfill their personal goals in their life contexts (Gottfredson, 2002; Lent et al., 1994). This perspective forms the foundation of longestablished person-environment fit theories that form the basis of career research and practice in counseling and I-O psychology (Dawis \& Lofquist, 1984; Holland, 1997; Lent et al., 1994; Schneider, 1987; Super et al., 1963; Wiernik \& Wille, 2018). It also underlies more recent career thinking, such as career construction and life designing models that draw on constructivist and social constructionism perspectives (Savickas et al., 2009). Recognizing the role of

Brenton M. Wiernik, Department of Psychology, University of South Florida; Bart Wille, Department of Training and Education Sciences; University of Antwerp; Anne-Grit Albrecht, Institute of Management and Organization, Leuphana University Lüneburg; Karl J. Petersen, Structural Motility, Institut Curie, UMR 144/CNRS.

Correspondence concerning this paper should be addressed to Brenton M. Wiernik, Department of Psychology, University of South Florida, Tampa, FL 33620. Email: brenton@wiernik.org 
individual choices in guiding careers does not preclude the existence or influence of social-structural factors on these choices and is not an "excuse" to justify societal or structural inequities (cf. Miner et al., 2018, p. 19). Indeed, addressing gender differences in STEM representation requires understanding the choices women make about their careers and the factors influencing these choices.

Following the familiar Attraction-SelectionAttrition framework (Schneider, 1987), to pursue STEM careers, women must (1) be attracted to STEM-related tasks, (2) be selected for STEM opportunities by relevant gatekeepers, and (3) choose to persist in STEM-relevant positions. A variety of individual and social-structural factors contribute to gender differences in STEM representation through each of these processes. A critical task for researchers and practitioners is to elucidate whether these factors reflect illegitimate barriers to women pursuing their preferred goals or legitimate differences in the career goals women and men choose to pursue.

\section{Attraction to STEM-related Tasks}

Numerous meta-analyses have documented that, in recent years and in countries with high levels of gender equality, gender differences in mathematical and complex problem-solving ability are negligible to small, indicating that gender differences in STEM do not result from differences in capability for these fields (Hyde, 2014). ${ }^{1}$ Men do score higher on spatial reasoning tasks (e.g., mental rotation); this difference is likely most relevant for STEM motivation, rather than competence, see below (Lubinski et al., 2001; Maeda \& Yoon, 2013). In contrast, girls and women more often perceive that they are less capable at math and science (Else-Quest et al., 2010). These misperceptions emerge in middle school (PerezFelkner et al., 2017) and likely result from socialstructural processes that encourage boys and discourage girls from pursuing STEM fields. These processes limit women's career exploration and are important targets for educational and social policy and intervention.

Although gender differences in STEM capability are small, differences in STEM motivation are large and have persisted over decades, even as differences for other fields have reduced or disappeared (Schulz \& Su, 2016; Su et al., 2009; Su \& Rounds, 2015). Men show much higher Realistic (technical-spatial) and somewhat higher Investigative (scientific) interests, whereas women show higher Artistic and Social (interpersonal, helping) interests. Women and men also differ in their typical within-person ability patterns. Women tend to show a balanced ability profile (relatively equal levels of verbal, quantitative, and spatial ability), whereas men tend to be more tilted toward spatial/quantitative ability (Lubinski et al., 2001; Wang et al., 2013). People pursue careers that take advantage of their personal strengths; women's balanced ability profiles may lead them to regard a wider range of STEM and non-STEM fields as viable options compared to men. These differences in interests and ability patterns appear to emerge in infancy and are associated with prenatal testosterone exposure (Berenbaum, 2017; Moore \& Johnson, 2008), indicating that these differences result from a mix of both sociocultural and more biological processes. These factors make it likely that, even in the absence of social-structural biases, fewer women than men would pursue some STEM fields, as these fields are less likely to match their psychological profile of interests and abilities, just as men's lower participation in psychology, sociology and health-related occupations likely in part reflects typical male patterns of interests and ability profiles (Lubinski et al., 2001; Wang et al., 2013).

Critically, one must recognize that STEM fields are not homogeneous. Gender differences in motivation and representation vary widely across STEM fields. For example, as shown in Table 1, although women are less likely to enter physics or mathematics, they are equally or more likely to pursue biological, medical, or many social sciences. These differences are related to fields' patterns of ability demands (balanced vs. exclusively spatial/quantitative) and focus on people versus things (Lubinski et al., 2001; Su \& Rounds, 2015).

\footnotetext{
${ }^{1}$ Gender differences in both means and variances are small, so gender differences in ability at the upper tails of the distribution also cannot account for differences in STEM representation (Hedges \& Friedman, 1993; Hyde, 2014).
} 
Table 1. Gender differences in employment and interest across STEM fields

\begin{tabular}{|c|c|c|c|}
\hline \multirow[b]{2}{*}{ STEM field } & \multicolumn{2}{|c|}{ Employment } & \multirow[t]{2}{*}{ Interests } \\
\hline & Women & Men & \\
\hline Social and behavioral sciences & & & -.33 \\
\hline Economics & $38 \%$ & $62 \%$ & \\
\hline Political science & $28 \%$ & $72 \%$ & \\
\hline Psychology & $73 \%$ & $27 \%$ & \\
\hline Sociology and anthropology & $68 \%$ & $32 \%$ & \\
\hline Other social sciences & $59 \%$ & $41 \%$ & \\
\hline Medicine and health occupations & $70 \%$ & $30 \%$ & $-.04^{\mathrm{a}} /-.40^{\mathrm{b}}$ \\
\hline Biological and life sciences & & & .19 \\
\hline Agricultural and food science & $48 \%$ & $52 \%$ & \\
\hline Biology and medical science & $53 \%$ & $47 \%$ & \\
\hline Forestry and conservation science & $20 \%$ & $80 \%$ & \\
\hline Physical sciences & & & .56 \\
\hline Chemistry (except biochemistry) & $32 \%$ & $68 \%$ & \\
\hline Earth science, geology, and oceanography & $23 \%$ & $77 \%$ & \\
\hline Physics and astronomy & $18 \%$ & $82 \%$ & \\
\hline Other physical sciences & $39 \%$ & $61 \%$ & \\
\hline Mathematics & $43 \%$ & $57 \%$ & $.38 \% .23^{\mathrm{d}}$ \\
\hline Computer and information science & $24 \%$ & $76 \%$ & .38 \\
\hline Engineering & $15 \%$ & $85 \%$ & .83 \\
\hline $\begin{array}{l}\text { Note. Employment data indicate percentages of men a } \\
\text { health care managers excluded; based on the } 201 \\
\text { NSF, 2017); interest data indicate meta-analytic obs } \\
\text { (2015); positive } d \text { values indicate men score higher; } \\
{ }^{c} \text { Mathematics interests; }{ }^{\text {d }} \text { Applied Mathematics intere }\end{array}$ & $\begin{array}{l}\text { employed } \\
\text { Survey of } \\
\text { alues for ba }\end{array}$ & ch STE & $\begin{array}{l}\text { d (teachers and } \\
\text { tes reported by } \\
\text { Su and Rounds } \\
\text { ervice interests; }\end{array}$ \\
\hline
\end{tabular}

\section{Selection into STEM Fields}

Given the small gender differences in STEMrelevant capabilities, disadvantages faced by women in selection for STEM careers must primarily reflect undesirable social-structural biases. For example, faculty search committees often consider irrelevant factors, such as family situation or spouse job prospects, for women but not for men (Rivera, 2017).

One particularly concerning selection bias concerns reliance on heuristics that apply descriptions of the population of women generally to female STEM applicants. For example, hiring managers may prefer male applicants for programming positions based on a belief that they are more motivated or experienced in this field. However, while women may in general have less computer science interest and experience than men, this is unlikely to be true for women who have expressed their interest in computing by applying to positions in this field. Such inappropriate inferences from general to specific populations are common in lay interpretations of psychological research on gender differences (e.g., James Damore's highly-publicized "Google memo”; Molteni \& Rogers, 2017).

\section{Persistence in STEM Fields}

Even after choosing to pursue a STEM career and overcoming numerous biases and socialstructural barriers to entry, women are also more likely to eventually leave their fields, as well as more likely to persist in lower-level STEM positions (e.g., to work as a nontenured instructor or researcher rather than as tenured faculty; NSF, 2014, Table 9-23). This differential attrition is in large part due to social-structural barriers, such as women leaving their fields due to experiences of 
bias, sexual harassment or misconduct, or toxic cultures that fail to support women (e.g., women are more likely to be passed over for awards and to be regarded as less “eminent”; Vazire, 2017). These issues are likely to be more prevalent in fields where women are less represented (King et al., 2010) and must clearly be remedied. However, attrition may also stem from gender differences in work values. For example, women tend to regard work-life balance as more important than men and to be less willing to spend 60 or more hours per week on their careers (Benbow et al., 2000; Hakim, 2006). These differences may lead women to regard features of currently available STEM careers, such as short-term job contracts and demands for frequent geographic mobility (e.g., for postdoc positions), pressure to work long hours, demands for uninterrupted productivity, and pressure to remain current on rapidly changing substantive and technical knowledge, as incompatible with their personal life goals. Choices to leave STEM that are driven by these factors are not so clearly problematic; it is difficult to fault someone for preferring a higher degree of work-life balance offered by a career track (though STEM careers themselves could be changed to be more balanced, see below).

\section{Implications for I-O Practice}

Considering the mix of individual differences and social-structural factors influencing women's career choices highlighted above, what are the implications for I-O psychologists seeking to increase female STEM representation? One approach is interventions to increase women's motivation for STEM tasks. Career interests tend to stabilize in early adolescence (Low et al., 2005). Female ability-confidence disparities also emerge during this period. Thus, interventions to increase female motivation for STEM must occur in elementary and middle school, rather than in settings more familiar to $\mathrm{I}-\mathrm{O}$ psychologists (i.e., universities and workplaces).

For I-O psychologists, a more immediate and effective approach is to address biases and provide support for those women who do choose to pursue STEM careers. Given gender differences in interests and ability perceptions, women are likely to continue to be a minority in applicant pools for STEM positions. Contrary to arguments that these differences render interventions to encourage or support women in STEM ineffective or quixotic (cf. Molteni \& Rogers, 2017), lower numbers of women pursuing STEM makes proactive, femaleaffirmative HRM practices more important. Biased evaluations, harassment, and feelings of tokenism can emerge more easily and have more deleterious effects when women are fewer in number. Thus, it is critical for I-O psychologists (1) to design standardized selection systems that prevent biased heuristics and consideration of inappropriate variables (e.g., spouse career opportunities), (2) to monitor organizational and professional cultures to prevent harassment, abuse, and inequitable evaluations for promotions and recognition, and (3) to provide individual support to women in STEM to prevent feelings of tokenism, discover aversive conditions that must be addressed, and help women to cope with experiences of bias and isolation. These efforts to accommodate low numbers of female STEM applicants and incumbents are critical to prevent women from being barred from or opting out of toxic STEM environments.

I-O psychologists can also help to address structural factors in STEM career paths that lead women to exit, such as organizational/professional cultures and incentives that limit work-life balance, offer little job or geographic stability, or interfere with partners' abilities to pursue their own careers. For example, researchers can promote acceptance of collaborative research projects that distribute responsibilities and rewards across team members, and organizations can create permanent positions at multiple hierarchical levels (e.g., permanent researcher positions, versus expecting early career scientists to work as temporary postdocs). Researchers, professional societies, grant agencies, and universities can also recognize the roles that chance events, subjective evaluations, and rater errors play in scientific evaluations and outcomes (Vazire, 2017) and promote reforms that allocate resources and rewards transparently and equitably, rather than based on "prestige" or "eminence" (making 
favorable outcomes more accessible for researchers generally). Creating cultures and STEM career paths that are more equitable, compatible with diverse lifestyle preferences, and amenable to work-life balance and healthy work habits is likely to both enhance women's persistence in STEM and well-being outcomes for STEM employees generally. Such changes would likely also improve other fields characterized by intense and possibly unreasonable career demands (e.g., law, politics, business).

Importantly, in any efforts to support women in STEM, either through individual support and guidance or by changing structures that enshrine bias or permit abusive behavior, $\mathrm{I}-\mathrm{O}$ psychologists and society at large must be careful to not dismiss women who choose other fields. Discussions of women in STEM sometimes imply that women choosing fields other than physical sciences or technology is inherently suspect or a "loss of talent” (Gibbs, 2014). We ask, "Is a woman who makes critical contributions to law, literature, sociology, or psychology lesser than a woman who contributes to physics or computer science?”. The goal of gender-conscious efforts by organizations, I-O psychology, and society at large should be to enable women to maximally realize their own goals and ambitions, not to dictate what those ambitions ought to be. Promoting gender equity in careers requires affirming the choices women make based on their individual differences, personal life goals, and social-structural influences, whether those choices are to pursue STEM or other fields.

\section{References}

Benbow, C. P., Lubinski, D., Shea, D. L., \& EftekhariSanjani, H. (2000). Sex differences in mathematical reasoning ability at age 13: Their status 20 years later. Psychological Science, 11(6), 474-480.

https://doi.org/10/bdsf4w

Berenbaum, S. A. (2017). Beyond pink and blue: The complexity of early androgen effects on gender development. Child Development Perspectives. Advance online publication. https://doi.org/10/gcp29q

Dawis, R. V., \& Lofquist, L. H. (1984). A psychological theory of work adjustment: An individual-differences model and its applications. Minneapolis, MN: University of Minnesota Press.
Else-Quest, N. M., Hyde, J. S., \& Linn, M. C. (2010). Cross-national patterns of gender differences in mathematics: A meta-analysis. Psychological Bulletin, 136(1), 103-127. https://doi.org/10/fqzhff

Gibbs, K., Jr. (2014, September 10). Diversity in STEM: What it is and why it matters. Retrieved January 4, 2018, from

https://blogs.scientificamerican.com/voices/diversity-instem-what-it-is-and-why-it-matters/

Gottfredson, L. S. (2002). Gottfredson's theory of circumscription, compromise, and self-creation. In D. Brown (Ed.), Career choice and development (4th ed., pp. 85-148). San Francisco, CA: Jossey-Bass.

Hakim, C. (2006). Women, careers, and work-life preferences. British Journal of Guidance \& Counselling, 34(3), 279-294. https://doi.org/10/c6m3x5

Hansen, J.-I. C. (2013). Personality and vocational behavior. In N. D. Christiansen \& R. P. Tett (Eds.), Handbook of personality at work (pp. 651-670). New York: Brunner-Routledge.

Hedges, L. V., \& Friedman, L. (1993). Gender differences in variability in intellectual abilities: A reanalysis of Feingold's results. Review of Educational Research, 63(1), 94-105. https://doi.org/10/bt6qnc

Holland, J. L. (1997). Making vocational choices: A theory of vocational personalities and work environments (3rd ed.). Odessa, FL: Psychological Assessment Resources.

Hyde, J. S. (2014). Gender similarities and differences. Annual Review of Psychology, 65, 373-398. https://doi.org/10/gckfxg

King, E. B., Hebl, M. R., George, J. M., \& Matusik, S. F. (2010). Understanding tokenism: Antecedents and consequences of a psychological climate of gender inequity. Journal of Management, 36(2), 482-510. https://doi.org/10/fqh4nd

Lent, R. W., Brown, S. D., \& Hackett, G. (1994). Toward a unifying social cognitive theory of career and academic interest, choice, and performance. Journal of Vocational Behavior, 45(1), 79-122. https://doi.org/10/bpdwrw

Low, K.-S. D., Yoon, M., Roberts, B. W., \& Rounds, J. B. (2005). The stability of vocational interests from early adolescence to middle adulthood: A quantitative review of longitudinal studies. Psychological Bulletin, 131(5), 713-737. https://doi.org/10/dcj

Lubinski, D., Benbow, C. P., Shea, D. L., EftekhariSanjani, H., \& Halvorson, M. B. J. (2001). Men and women at promise for scientific excellence: Similarity not dissimilarity. Psychological Science, 12(4), 309317. https://doi.org/10/bb42g2 
Maeda, Y., \& Yoon, S. Y. (2013). A meta-analysis on gender differences in mental rotation ability measured by the Purdue Spatial Visualization Tests: Visualization of Rotations (PSVT:R). Educational Psychology Review, 25(1), 69-94. https://doi.org/10/gckf3j

Miner, K. N., Walker, J. M., Bergman, M. E., Jean, V. A., Carter-Sowell, A., January, S. C., \& Kaunas, C. (2018). From "her" problem to "our" problem: Using an individual lens versus a social-structural lens to understand gender inequity in STEM. Industrial and Organizational Psychology, 11(1).

Molteni, M., \& Rogers, A. (2017, August 15). The actual science of James Damore's Google memo. WIRED. Retrieved from https://www.wired.com/story/thepernicious-science-of-james-damores-google-memo/

Moore, D. S., \& Johnson, S. P. (2008). Mental rotation in human infants: a sex difference. Psychological Science, 19(11), 1063-1066. https://doi.org/10/fsmdbf

NSF. (2014). Survey Doctorate Recipients: 2013. Alexandria, VA: National Science Foundation, National Center for Science and Engineering Statistics. Retrieved from https://ncsesdata.nsf.gov/doctoratework/2013/

NSF. (2017). Women, minorities, and persons with disabilities in science and engineering (Data Tables No. NSF 17-310). Arlington, VA: National Science Foundation, National Center for Science and Engineering Statistics. Retrieved from https://www.nsf.gov/statistics/2017/nsf17310/data.cfm

Perez-Felkner, L., Nix, S., \& Thomas, K. (2017). Gendered pathways: How mathematics ability beliefs shape secondary and postsecondary course and degree field choices. Frontiers in Psychology, 8. https://doi.org/10/gcp29k

Rivera, L. A. (2017). When two bodies are (not) a problem: Gender and relationship status discrimination in academic hiring. American Sociological Review, 82(6), 1111-1138. https://doi.org/10/gck9hn

Savickas, M. L., Nota, L., Rossier, J., Dauwalder, J.-P., Duarte, M. E., Guichard, J., ... van Vianen, A. E. M. (2009). Life designing: A paradigm for career construction in the 21st century. Journal of Vocational Behavior, 75(3), 239-250. https://doi.org/10/dc4rrk

Schneider, B. (1987). The people make the place. Personnel Psychology, 40(3), 437-453. https://doi.org/10/brhpmf

Schulz, N., \& Su, R. (2016, April). Gender differences in leadership interests across generations: a metaanalysis. Poster presented at the Society for Industrial and Organizational Psychology conference, Anaheim, CA. https://doi.org/10/chwc
Su, R., \& Rounds, J. (2015). All STEM fields are not created equal: People and things interests explain gender disparities across STEM fields. Frontiers in Psychology, 6, 189. https://doi.org/10/gcz6s8

Su, R., Rounds, J. B., \& Armstrong, P. I. (2009). Men and things, women and people: A meta-analysis of sex differences in interests. Psychological Bulletin, 135(6), 859-884. https://doi.org/10/fqw3vp

Super, D. E., Starishevsky, R., Matlin, N., \& Joraan, J. P. (Eds.). (1963). Career development: Self-concept theory. New York: College Board.

Vazire, S. (2017). Our obsession with eminence warps research. Nature, 547(7661), 7. https://doi.org/10/gcpt6g

Wang, M.-T., Eccles, J. S., \& Kenny, S. (2013). Not lack of ability but more choice: Individual and gender differences in choice of careers in science, technology, engineering, and mathematics. Psychological Science, 24(5), 770-775. https://doi.org/10/33t

Wiernik, B. M., \& Wille, B. (2018). Careers, career development, and career management. In D. S. Ones, N. Anderson, C. Viswesvaran, \& H. K. Sinangil (Eds.), The SAGE handbook of industrial, work and organizational psychology (2nd ed., Vol. 3). London, United Kingdom: Sage. https://doi.org/10.4135/9781473914964.n25 